\title{
Instructional programs for psychology: A review and analysis
}

\author{
DOUGLAS B. EAMON \\ University of Houston-Clear Lake, Houston, Texas \\ and \\ DARRELL L. BUTLER \\ Ball State University, Muncie, Indiana
}

\begin{abstract}
This paper presents 10 general observations about current software for instruction in psychology and examines selected examples employing four instructional techniques for computer-assisted instruction. We find that although the number of programs employing experimental or dataoriented approaches to psychology as a primary vehicle of instruction is increasing, tutorial drill and practice programs and gaming are not well represented.
\end{abstract}

Two years ago, a "sampler" of microcomputer (mostly Apple) programs usable for research and/or instruction in psychology included abut 25 programs and/or program sets (Eamon, 1983). About 15 were directly related to, or had as a primary use, instructional applications; the remainder were statistical packages or what we might now call "miscellaneous." A more recent listing of programs for psychologists (Academic Computing Center of Gettysburg College, 1984) included 40 programs or program sets we could reasonably identify as instructionally oriented.

In this paper, we make 10 general observations about the current state of instructional computing in psychology as represented by the programs in the Gettysburg Software Guide and provide a discussion of the character of these programs. A companion paper in this issue (Butler \& Eamon, 1985) considers statistical programs in particular; here, our focus is on programs designed for computer-assisted instruction (CAI) in a classroom or laboratory setting.

\section{GENERAL OBSERVATIONS ON AVAILABLE COURSEWARE FOR PSYCHOLOGY}

(1) If program availability may be considered a mea-

Reprints of the paper may be obtained from Douglas B. Eamon, Box 108, University of Houston-Clear Lake, 2700 Bay Area Blvd., Houston, TX 77058 . This paper is a companion to Butler, D. L., \& Eamon, D. B., "An evaluation of statistical software for research and instruction," Behavior Research Methods, Instruments, \& Computers (this issue), reprints of which may be obtained from Darrell L. Butler, Psychological Sciences, Ball State University, Muncie, IN 47306. Many of the programs discussed in this paper are listed in Academic Computer Center of Gettysburg College, Computing in Undergraduate Psychology: Software Guide, Gettysburg, PA, which may be obtained for a nominal fee from that institution. This Software Guide contains brief descriptions of many of these programs, as well as ordering information and prices. Readers wishing additional information regarding programs for microcomputers may write to the first author at the address above. sure of preference, the microcomputer is clearly the "computer assister" of choice: Of the 40 program sets listed in the Gettysburg Guide, 33 were available in a microcomputer version. Among microcomputers, the Apple II was by far the most popular: Every instructional program available for microcomputers was available in an Apple version. Twenty-six of the 33 programs for microcomputers were available only on the Apple.

(2) Most software seems to be oriented towards experimental psychology, particularly replications or simulations of classic experiments or experimental situations, data collection, statistical analyses, and methodology. That is, even those programs that present information about, for example, learning theory or cognitive development use as the primary instructional vehicle simulation of experimental results. Of the 40 instructional programs on the Gettysburg software list, we could find only 4 that presented information in a manner not directly related to an experimental technique or statistical procedure. Two of these were games that made no attempt to convey substantive material about psychology [Tribbles (Von Blum \& Hursh, 1976) and Baffles (Spain, 1983)], 1 was a tutorial on the nervous system [Nervous System, (Carolina Biological Supply, 1983)], and 1 was ELIZA (Artificial Intelligence Research Group, 1982). Clearly, software developers place an extraordinary emphasis upon, and apparently have an astonishing confidence in, simulation of experiments as a pedagogical strategy.

Butler and Kring's (1984) survey of faculty on present and potential uses of computers in psychology also indicated such a preference, but not nearly as dramatic as the distribution of available programs would suggest. Only $33 \%$ of the faculty presently using computers for instruction in their survey reported that they used the computer in "student laboratories," although $86 \%$ reported that they would be willing to do so.

(3) Programs suitable for instruction in the cognitive areas (especially memory and perception) seem to be ex- 
traordinarily well represented. This may be due to the shift in theoretical emphasis in psychology as a discipline toward these views, as well as to the more regular use cognitive psychologists may make of microcomputers in their research laboratories. Still, we suggest that the relatively poorer representation of instructional materials in such areas as physiological psychology, conditioning, personality, social and industrial psychology, and other areas should be addressed and corrected.

(4) Castellan (1983) distinguished "data-generator" programs, which generate artificial data representative of various experimental conditions manipulated by the student, from "experiment simulators," or programs in which the student uses the program to actually "run" subjects (often him/herself) and obtain in that manner "real" data. Of the 36 programs identified above as experimentally oriented, only about a fourth were data generators; the remaining three-fourths were experiment simulators. This is a peculiar and interesting contrast to what we observe in programs running on mainframe computers, nearly all of which seem to be of the data-generator type [e.g., EXPERSIM (Main, 1978), LABSIM (Edwards, 1984), etc.]. We believe this results from two considerations: (a) It is relatively difficult to collect time-dependent responses on mainframe computers, but easy to do so on a microcomputer, and (b) microcomputers are being used more regularly by psychology teachers interested in timedependent responses than by psychology teachers with other kinds of interests (see Observation 3, above).

(5) There is a growing tendency to produce software in related sets, rather than as individual programs. This has both good and bad implications. On the one hand, it suggests that courseware developers are probably spending more time and effort in the planning and implementation of the materials than may have been true in the past, when singleton programs seemed more common. This is, of course, good. On the other hand, we think that the availability of such program sets may discourage novice programmers and those with fewer resources or less time from attempting to write programs. Innovative approaches to courseware design, often first implemented as individual programs, may thus be discouraged.

(6) There is a tendency toward commercialization of courseware. Whereas it was common in the past to write programs and hand them out rather freely to anyone who was interested, we find relatively fewer such programs available today. We expect that this is related to the increased time and effort spent on program development, which should, of course, be reflected in some compensation for the programmer. Although considerable concern has been expressed regarding distribution of courseware by book publishers, we do not think this is necessarily bad (although some of the courseware itself may be bad). Some publishers are including the programs as free inducements to purchasing their texts, not as profit-making productions in themselves. This means, of course, that the quality of some of the materials may not be as high as instructors would like, but it also suggests that the book publishers will not, for the same reason, become the dominant force in the courseware market.

(7) Current programs for instruction make little use of hardware peripherals. Some "older" programs required such devices as game paddles, lowercase character generators (for the Apple), clocks, I/O interfaces, special monitors, and other such plug-ins. We believe that the tendency toward commercialization may be partly responsible for this newer hardwareless environment, but we view it with mixed feelings. Although the absence of such devices makes the programs more widely usable (and saleable), there are many instances in which programs could and should (at least optionally) be written to take advantage of such devices. It is now typical in the research laboratory that special hardware configurations are required to perform certain stimulus-presentation or datacollection functions. To the degree that the instructional microcomputer laboratory lacks these configurations, we may expect a loss of fidelity in this respect, and whatever consequences might be attendant. It should be remembered that one of the much touted virtues of using microcomputers in the student laboratory was that it was possible to (cheaply and easily) replicate many of the more expensive and complicated features of the research laboratory.

(8) Courseware is becoming more sophisticated. Virtually every available program is menu driven and provides instructions (although these instructions vary in quality and completeness) on screen to the user. Few require much in the way of programming or computer sophistication other than the ability to turn the computer on. Many programs are implementing well-designed graphics in the presentation of materials and are employing a mixture of instructional techniques. None of the programs we tested "crashed" unexpectedly. Most of the programs perform input checks, and many allow the use of special function keys (e.g., ESCAPE) to page backwards, return to the main menu, etc. Although we saw occasional "bugs," they were rare and usually had no more serious consequences than the program's returning to the directory without performing the assigned or expected function.

(9) There are only a limited number of distributors for "good" instructional materials. By far the greatest collection of software for psychologists is available through CONDUIT and Life Sciences, Inc. No other distributor comes even close to these in terms of number and quality of materials. We believe that part of this is due to the influence of individuals who have been associated with these organizations or who have contributed numbers of programs to them. In addition, the thorough review procedures used by these two organizations encourage new developers of software (particularly untenured professors or those seeking peer recognition of their work) to submit programs to them. We are unsure of what to make of this, but we doubt that it could be a good omen for the future of instructional computing in psychology. Our 
guess is that, just as book publishers have discovered, other distributors have learned there just isn't much money in it.

(10) We observe a shifting trend in written software documentation. For example, CONDUIT's earlier programs for instruction in psychology (e.g., Bewley, 1974) were accompanied by extensive student manuals, instructor's manuals, and implementation guides. More recent materials (e.g., Fazio \& Backler, 1983a, 1983b, 1983c) provide very little if any of these materials. In part, this is due to courseware implementation on the microcomputer, which requires little or nothing in the way of installation guides, as opposed to mainframe programs, which have to be accompanied by instructions for making the systems work on various machines. But we also believe this reflects a shift in attitude toward smaller, internally documented programs and, more importantly, toward courseware that can be used independently of workbooks or other written supporting materials.

We are not sure about the consequences of this shift, but expect that it may be reversed if financial rewards come to play a more important role in software distribution. This is because software developers may be realizing that they can do better financially by selling the software cheaply and then relying on royalties from the written supporting materials for continuing income. Although only one program may be sold to each institution, a software system that requires each student to have a workbook or other printed materials may be a source of more reasonable financial return.

\section{INSTRUCTIONAL PROGRAMS FOR PSYCHOLOGY}

Castellan (1983) identified four modes of instructional computing: drill and practice, data generators, experiment simulators, and gaming. In the following section, we discuss software availability for instruction in psychology in each of these four modes. Time and space limitations prevent an examination of every program or program set, but we consider those discussed to be representative of the current state of instructional computing in psychology. Readers who wish for a more complete list may consult Computing in Undergraduate Psychology: Software Guide (Academic Computing Center, 1984).

\section{Drill and Practice}

These programs are designed to present substantive information in a structured way, that is, as in programmed instruction, interactive question-and-answer sessions, online testing, etc. In contrast to what might be expected given psychologists' well-known interest and history with such techniques, we were puzzled to find that there were few programs of this type suitable for instruction in psychology. Indeed, the only clear-cut drill and practice programs we know of for psychology are tutorial systems in which the instructor types in a set of statements that the student "pages" through, or a set of questions to which the student responds.

Grasp-It (Peterson \& Safdie, 1983) is an example of this type of application. This program is available in a version that presents information taken from a popular introductory psychology text. Two modes are used: In the first (study) mode, the material is simply presented one screen at a time until completed. In the second (test) mode, multiple-choice questions are presented; incorrect answers are followed by information about why they are incorrect. As Safdie (1984) pointed out, such authoring systems are seriously limited because of their text-frame structure, and often become simple "page turners." Grasp-It is particularly limited in this respect: In addition to the entirely textual (uppercase only) presentation of materials, the program makes no screen adjustments for beginnings or endings of paragraphs, or for mixing the study (presentation of materials) component with the test component.

Statmaster (Levy, Froming, \& Belcher, 1983) contains segments that may be classed as drill and practice, although this set is really a carefully designed mix of instructional modes. The clarity and quality of its drill and practice aspects, however, stand in clear contrast to materials prepared with authoring systems. Statmaster is examined in this issue (Butler \& Eamon, 1985).

We are also aware of some self-help programs that provide a greater variety of styles of information presentation, but because we were unable to obtain examination copies, we are uncertain of their classroom potential.

We draw two conclusions about drill and practice programs. First, there is a considerable need for such programs in psychology. As Castellan (1983) observed, the literature on problem solving shows that expertise depends upon a foundation of a large number of facts. Drill and practice is often a fruitful way to learn such facts. Producers of instructional programs for psychology have apparently not responded to this need. Indeed, a perceptible disdain for drill and practice as an instructional mode in psychology seems to be characteristic of many potential users. Our second conclusion is that even the few programs of which we are aware fall far short of the quality of programming we expected to find in this area. That good drill and practice programs can be written is demonstrated by portions of Statmaster and Algebra Drill and Practice (Detmer \& Smullen, 1981), a program psychology students might well benefit from, but which is not directly oriented toward psychology instruction.

\section{Data Generators}

Data generators allow the student to select and manipulate certain variables that are used as parameters for generating artificial data. These data presumably resemble those that might be obtained if the "experiment" were run in a real-world situation.

Several well-known sets of data generators are available for mainframe computers. Growing numbers of this 
type of program are becoming available for microcomputers. It is interesting to observe that, although the most widely known and available data generators for mainframe computers (e.g., EXPERSIM, LABSIM, etc.) are designed around one or two "system" programs accessed by the simulation modules (which actually produce and print the data), most microcomputer versions are of the "standalone" variety (i.e., each uses its own data-generation procedures).

We perceive a continuum from drill and practice to data generators, with many programs employing both modes of instruction. Most of the programs that appear under this heading (and that of "experiment simulators," below) present substantive information as well as generate data, and may thus take up some of the slack in drill and practice tutorial materials.

SAMP: Survey Sampling (Gilbert, 1984) contains sizeable segments that present materials in the tutorial mode, but the presentation is much more pleasing, well controlled, and, we expect, instructive than similar attempts using authoring systems. In that respect, it provides a good contrast to the use of authoring systems versus developing special-purpose materials. SAMP considers the problem of obtaining information regarding voters opinions about a proposal to redevelop the center of a town. Information about sampling in general is presented, as well as specific information about simple random sampling, cluster sampling, stratified sampling, and quota sampling. Each discussion is followed by an opportunity to use the sampling procedure to "survey" the population; results based on the procedure are graphically presented using informative and well-labeled histograms that can be compared with each other by simply pressing a key. Statistics for each sample are also shown, and the student is invited to compare their efficacy.

The mix of tutorial materials and data generation to illustrate the sampling procedures appears clear and pedagogically well designed.

Other than $S A M P$, the programs that provide the greatest amount of direct instruction in the tutorial format are the series of three programs Topics in Research Methods: Main Effects and Interactions (Fazio \& Backler, 1983a), Topics in Research Methods: Survey Sampling (Fazio \& Backler, 1983b), and Topics in Research Methods: Power (Fazio \& Backler, 1983c). In all cases, much of the instruction occurs through student manipulation of variables and examination of the outcomes of the results of these manipulations on data generated by the programs.

Of the three, Topics in Research Methods: Main Effects and Interactions (Fazio \& Backler, 1983a) probably contains the greatest amount of direct tutorial materials. The content focus of the materials is an experiment scenario involving the effects of communicator attractiveness on attitude change. Information on computation and interpretation of main effects and interactions for $2 \times 2$ and 2 $\times 2 \times 2$ designs is included using variables related to the scenario. The program makes liberal use of mixed graphics and text. Especially interesting is the graphical presentation of data, along with information on graphing techniques for factorial designs and the interpretation of graphs.

Topics in Research Methods: Survey Sampling (Fazio \& Backler, 1983b) presents some general information and terminology regarding survey sampling and then allows the student to conduct a "survey" of a population by using either simple random sampling or stratified sampling. The student may select any one of six questions (reduction of government spending, prayer in schools, nuclear power, busing, desegregation, and need for reductions in inflation vs. unemployment). Sample sizes are selected, and the results of the sampling are shown graphically. A comparison of simple random sampling versus stratified sampling can also be done.

Topics in Research Methods: Power (Fazio \& Backler, $1983 \mathrm{c}$ ) focuses on an experiment testing the efficacy of a device that signals homeowners when outside temperature is low enough to allow turning off the air conditioner. This scenario permits students to observe differences due to changing sample size, increasing the reliability of the dependent measure, increasing the homogeneity of the sample, using matched pairs, and using repeated measures. A second part of the tutorial allows students to design their own experiments and observe the outcomes of their experiments in data produced by the programs. F and $p$ values are shown for all results.

All of these programs are accompanied by short "Student Notes," and all appear to be pedagogically well designed and very usable.

FIRM: Florida InteRactive Modeler (Levy \& Durnin, 1981) represents the most sophisticated data generator we have seen that is available for microcomputers. It is based on the earlier mainframe program EXPERSIM (Main, 1978). FIRM uses a common linear, additive model of analysis of variance to generate data. Driver routines handle student input, check for range errors, and generate appropriate statistical output.

Two sets (volumes) of models are available. Volume I, "The nature of attitudes and attitude change," consists of three models: The Counterattitudinal Behavior Model (cognitive dissonance), The Sleeper Effect Model (attitude change generated by low credibility source), and The Persuasion Model (characteristics of communicator, communication, and audience). Volume II, "Interpersonal Dynamics," contains The Crowding Model (characteristics of the room, intrasubject characteristics, interpersonal characteristics), The Conformity Model ("person" and "situational" variables), and The Aggression Model (relation of stimulus-cue association and frustration to aggression).

Particularly useful in the FIRM package is the Florida General Simulator, a program that allows the user (instructor) to create models interactively by responding to prompts for names, type, weights, effects, and error terms for variables, which are then used to generate artificial data using the linear, additive procedure. The system can 
also incorporate BASIC programs for more complex models.

The examples of data generators we have chosen represent the best of these types of applications. There are a number of other data generators available from individuals and other sources that vary in programming sophistication and classroom usability. Our conclusions regarding these programs are that, first, there is a wider variety of content areas represented in this type of instructional mode than in any other mode. Second, virtually all of these programs generate numbers as data. It would be possible, and we believe potentially instructive, to create programs that produce, for example, movements of objects or verbal (textual) responses as "data." Third, there is a wide range of student knowledge and sophistication required to use the programs, ranging from virtually none (e.g., SAMP) to considerable (e.g., FIRM). This is probably due to the instructional intent and flexibility of the programs, which range from largely introductory tutorials to teaching advanced experimental techniques.

\section{Experiment Simulators and Generators}

Experiment simulators. Experiment simulators are designed to allow the student (often him or herself) to run "real" subjects in actual experiments. The program acts as experimenter to present instructions and stimuli, collect responses, and display or store results for later statistical analysis. The experiments are usually "classics" or are assumed to be particularly instructive.

The earliest experiment simulator of which we are aware is the collection Cognitive Psychology (Bewley, 1974), which runs on mainframe computers. The first commercially available simulator for microcomputers was probably Perera's (1979) collection of 23 Computer Programs for Experimental Psychology, originally written on a TRS-80 and later converted to the Apple II (Perera, 1981). Levy, Fischler, and Grigg's (1979) Laboratory in Cognition and Perception was first implemented on a minicomputer system and was converted to an Apple II version in 1981 . Both of these sets are still widely used.

These relatively recent applications have become especially popular over the last few years and now outnumber data generators. Perhaps this reflects the orientation of many instructors who use microcomputers for their own research and are also instructors in research-oriented courses.

These applications tend to require the greatest amount of previous student knowledge about content and methodology. The programs are almost always accompanied by extensive descriptions of the background of the experiments in reading materials or workbooks, with little or no such information provided as on-screen tutorials.

Computer Programs for Experimental Psychology (Perera, 1981) is a collection of programs that are largely simulations of experiments for "traditional" experimental psychology laboratory exercises. The programs include "Reaction time," "Quantification of the Muller-Lyer figure," "Quantification of the horizontal-vertical illu- sion, the Poggendorf illusion, line-length judgments, and size of rectangle judgments," "Concept formation," "Verbal learning," "Multiple-field tachistoscope," "Visual illusion demonstration," "Psychophysical scaling of line length using category scaling or magnitude estimation," "Visual acuity," "Operant conditioning," "Latency analyzer and histogram plotter," "Interresponse time analyzer and plotter," "Event recorder," "Cumulative recorder," "Human maze learning," "Signal detection," "Pursuit rotor," "Mirror tracing," "Operant conditioning control program," and "Laboratory control system."

The programs collect data and produce appropriate statistical analyses. Most are engaging and appear very usable in the instructional laboratory.

They are not menu driven and thus require some knowledge of the computer to operate (e.g., how to "RUN" a program from the disk); some require special hardware. Although short user notes are provided, these notes are aimed at the instructor rather than the student and are largely concerned with program structure and implementation. We found the Apple versions of the programs less well implemented than the TRS- 80 versions, particularly in terms of speed, screen display, and keyboard $\mathrm{I} / \mathrm{O}$ characteristics.

They differ in important respects from the Laboratory in Cognition and Perception (below), particularly in that some allow the student/experimenter to enter or modify various experimental parameters, such as number of trials, stimuli, intertrial intervals, etc. The "Laboratory Control System' is an especially interesting program that extends this feature greatly by facilitating the design and implementation of virtually any data-collection process. State programming techniques (cf. Snapper, Kadden, \& Inglis, 1982) are established via a menu of questions provided by the program, which then produces appropriate control sequences (states) to drive a hardware interface for up to six inputs and eight outputs, and using up to 20 transitions. Other programs of this type are discussed below as "experiment generators."

The Laboratory in Cognition and Perception (Levy et al., 1979) contains 11 simulations. It was designed as a free-standing laboratory course to parallel the substantive material covered in a lecture course in cognition and perception. As much as anything, this collection appears to have set the "tone" of programs in this area. It relies heavily on the accompanying instructor's guide and student manual, which provide suggestions on the use of the programs, background information for students, and datarecording forms.

The programs, all replications of well-known results, include "The method of constant stimuli," "Signal detection," "The span of apprehension," "Iconic memory," "Feature detection," "Pattern interpretation," "Retrieval from short-term memory," "Short-term memory," "Comparing visual and semantic information," "Concept learning," and "Reasoning from prose." 
The programs are almost entirely text oriented and make no provisions for student manipulation of the independent variables, stimuli, or dependent measures. Most employ only within-subjects designs. Data are shown on screen for the student experimenter to copy or are printed on an attached printer, but are not stored to disk for later recovery.

Even with these rather severe restrictions, this set of programs remains remarkably popular, current, and usable. If an institution has any experiment simulators, it probably has this set.

Computer Lab in Memory and Cognition (Keenan \& Keller, 1982) is a collection of 14 programs in five topic areas, including "Levels of processing" (two experiments), "Encoding specificity" (three experiments), "Semantic memory", (one experiment, two simulations, one demonstration), "Sentence-picture verification" (one experiment, one demonstration), and "Constructive processes in prose comprehension"' (three experiments). These programs operate similarly to those in the Laboratory in Cognition and Perception and employ similar pedagogical approaches. Their content focus is on long-term memory and discourse processing, as opposed to perception and short-term memory. They are, however, somewhat more flexible than those in Cognition and Perception, in that they allow student manipulation of certain experimental parameters and include demonstrations and simulations (data generation) as well as experiment simulation.

Data from experiments are stored in a common class data file, which can be easily recovered for analysis by the class. We found the student manual for this set of programs to be somewhat more complete and instructive than that in the Cognition and Perception set. Most programs are entirely text oriented.

Experiment generators. Allowing students to control experimental conditions suggests a flexibility not usually found in experiment simulators. In some cases, the student (or instructor) may wish to use entirely different stimuli or different conditions from those the original "classic" experiment supplied. Depending upon the number and type of modifications that can be made, the resulting experiments may be more new creations than simulations of classic experiments. Although the Computer Lab allows some modifications, they are generally limited to a few items within restricted domains. At the other end of the scale are a few programs that are specifically designed to allow the creation of entirely new experiments. Perera's "Laboratory control system" is one of these. Others in this category are APT: Apple Pascal Tester (Poltrock \& Foltz, 1982), CEDATS: Cognitive Experimental Design and Testing System (Eamon, 1982), Experiment Control Program (Gordon, 1981), Software Methods for Experimental Psychology (Dlhopolsky, 1984), Cognitive Testing Station (Digitry Company, Inc., 1981), and Apple-Psych (Osgood, 1982).

All of these allow the student or instructor to enter information that controls the presentation of stimuli and the collection of responses. They vary considerably in assumed knowledge of computer operation and programming skill required, as well as in flexibility. As might be expected, it is generally true that the greater the flexibility of the program, the more expertise and effort is required to create experiments.

Some of these programs are equipped for automatic storage and/or analysis of data collected through built-in statistical routines or through interfacing to other statistical packages. Most require some hardware I/O devices. We shall defer further consideration here; a later paper will undertake a discussion and comparison of them.

We have here only touched on a few of the sets of programs in the experiment-simulation/experimentgeneration category. Surveying these, as well as others of which we are aware, leads to several general conclusions. First, there are a lot of them, particularly if each program in a set is considered individually. Second, more than any other category, these programs are collected into related sets accompanied by extensive student and instructor documentation. Third, a relatively large number of these are related to cognitive psychology, particularly memory and perception. Fourth, a great many of the programs collect response time data as opposed to other sorts of dependent measures (e.g., verbal). Fifth, as with the data generators, the stimuli and responses are largely textual; little use is made of graphics or auditory stimuli. Sixth, these programs seem to be the most complex of the four categories, frequently requiring program overlays, creation of disk data files, and elaborate user protection routines. Seventh, these programs require the greatest amount of student knowledge and sophistication to use. This is particularly true of the "experiment generators," which are always accompanied by lengthy manuals.

\section{Gaming}

Of all the instructional modes for psychology, gaming is the least well represented. We obtained only two programs in this category, although we are aware that at least one other exists. Neither of the two we examined was directly related to a particular content area in psychology, although both could easily be used in courses in introductory psychology or in experimental methodology.

In Baffles (Spain, 1983), the student player attempts to locate the position and orientation (left or right slanted) of a group of deflectors ("baffles") within a box-shaped area shown graphically on the screen. Baffle locations are defined by their $\mathrm{x}, \mathrm{y}$ coordinates. Each baffle is tilted $45^{\circ}$ to the left or right so that a "laser beam" directed toward it from any of the four sides of the box will be deflected if it hits a baffle; the position where a laser enters the box and the position where it emerges are clues to the location of baffles within it. Baffles may be used as an introduction to hypothesis testing in introductory courses or in methodology courses. Students find it very attractive and soon learn to carefully select their "inputs"' so as to provide the maximum amount of information (scores 
based on the number of lasers needed to correctly detect the presence of all of the baffles are produced at the end of the game). As the complexity of the game increases (by adding more baffles), students often begin to exchange strategies, and the resulting discussion can be a good introduction to scientific hypothesis testing and its limitations.

In Tribbles (Von Blum \& Hursh, 1976), the student tests hypotheses about the "reproductive" behavior of creatures on a distant planet. Although originally designed for biology students, it could be an excellent adjunct to an introductory course in research methodology, for the same reasons Baffles might be used there.

The few programs using gaming as an instructional technique in psychology suggest our single and most obvious conclusion: There could, and should, be more of these programs. The nonthreatening entertainment and attractive character of gaming should be further explored. The abstract, non-content-oriented approach of these two examples might be extended to additional games more closely allied with traditional psychological methodology (multiple subject observations, one-way and factorial designs, correlations, etc.). Other gaming techniques might focus on content-related subject matter that may be of intrinsic interest to students.

\section{REFERENCES}

Academic Computing Center of Gettysburg College. (1984). Computing in undergraduate psychology: A practicum. Software Guide. Gettysburg, PA: Author.

Artificial Intelligence Research Group. (1983). ELIZA [Computer program]. Los Angeles, CA: Author.

BEWLEY, W. L. (1974). Cognitive psychology: A computer-oriented laboratory manual. Hanover, NH: Project COMPUTe.

Butler, D. L., \& EAmon, D. B. (1985). An evaluation of statistical software for research and instruction. Behavior Research Methods, Instruments, \& Computers, 17, 352-358.

BUTLER, D. L., \& KRING, A. M. (1984). Survey on present and potential instructional use of computers in psychology. Behavior Research Methods \& Instrumentation, 16, 180-182.

Carouna BIological Supply. (1983). Nervous system [Computer progam]. Durham, NC: Author.

Castellan, N. J. (1983). Strategies for instructional computing. Behavior Research Methods \& Instrumentation, 15, 270-279.

Detmer, R. C., SMullen, C. W. (1981). Algebra drill and practice [Computer program]. Iowa City, IA: CONDUIT.

Digitry Company, INC. (1981). Cognitive testing station: Reference manual. Edgecomb, ME: Author.
DLHOPOLSKY, J. G. (1984). Software methods for experimental psychology. Bayport, NY: Life Sciences Associates.

EAMON, D. B. (1982). CEDATS: A cognitive experimental design and testing system. Behavior Research Methods \& Instrumentation, 14, 142-145.

EAMON, D. B. (1983). Microcomputer programs for instruction in psychology. Collegiate Microcomputer, 1, 11-18.

EDWARDS, R. E. (1984), LABSIM [Computer program]. Kent, WA: Educational Software Systems.

FAZIO, R. H., \& BACKLER, M. H. (1983a). Topics in research methods: Main effects and interactions [Computer program]. Iowa City, IA: CONDUIT

FAZIO, R. H., \& BACKLER, M. H. (1983b). Topics in research methods: Survey sampling [Computer program]. Iowa City, IA: CONDUIT.

FAZIO, R. H., \& BACKLER, M. H. (1983c). Topics in research methods: Power [Computer program]. Iowa City, IA: CONDUIT.

GILBERT, G. N. (1984). SAMP: A computer-aided learning package for teaching survey sampling [Computer program]. Iowa City, IA: CONDUIT.

GORDON, B. (1981). Experiment control program [Computer program]. Minneapolis, MN: Project services.

Keenan, J. M., \& Keller, R. A. (1982). Computer lab in memory and cognition [Computer program]. Iowa City, IA: CONDUIT.

LEVY, C. M., \& DURNIN, M. W. (1981). FIRM: Florida interactive modeler [Computer program]. Iowa City, IA: CONDUIT.

LeVY, C. M., FisChLER, I. S., \& GRIGGS, R. A. (1979). Laboratory in cognition and perception [Computer program]. Iowa City, IA: CONDUIT.

Levy, C. M., Froming, W. J., \& Belcher, M. (1983). Statmaster. [Computer program]. Boston, MA: Little, Brown.

MAIN, D. B. (1978). The implementation of EXPER SIM. EXPER SIM readings. lowa City, IA: CONDUIT.

OSGOOD, G. (1982). Apple-psych [Computer program]. Eugene, OR: University of Oregon, Department of Psychology.

Perera, T. B. (1979). Computer programs for experimental psychology [Computer programs]. Bayport, NY: Life Science Associates.

PERERA, T. B. (1981). A laboratory in experimental psychology using the TRS-80. Behavior Research Methods \& Instrumentation, 13, 195-197.

Peterson, K., \& SAFDIE, R. (1983). GRASP-IT: A computerized authoring system for educators [Computer program]. New York, NY; Harper \& Row.

Poltrock, S. E., \& Foltz, G. S. (1982). An experimental psychology laboratory system for the Apple II computer. Behavior Research Methods \& Instrumentation, 14, 103-108.

SAFDIE, R. (1984, Winter). To program or not to program. Network: The newsletter for psychology teachers at two-year colleges, 2, 2-3. (Available from Ann Rogers, Educational Affairs Office, American Psychological Association, 1200 Seventeenth Street NW, Washington, DC 20036)

SNAPPER, A. B., KADden, R. M., \& INGLIS, G. B. (1982). State notation of behavioral procedures. Behavior Research Methods \& Instrumentation, 14, 329-342.

SpaIN, J. S. (1983). Baffles [Computer program]. Iowa City, IA: CONDUIT.

Von Blum, R., HURSH, T. M. (1976). Tribbles: An introduction to the scientific method [Computer program]. Iowa City, IA: CONDUIT. 